Check for updates

Cite this: RSC Adv., 2018, 8, 16260

\title{
Sorption of tetracycline on biochar derived from rice straw and swine manure $\uparrow$
}

\author{
Hua Wang, ${ }^{\text {ab }}$ Chengran Fang, (D)*ab Qun Wang, ${ }^{\text {ab }}$ Yixuan Chu, ${ }^{\text {ab }}$ Yali Song, ${ }^{\text {ab }}$ \\ Yongmin Chen ${ }^{\mathrm{ab}}$ and Xiangdong Xue $\mathrm{e}^{\mathrm{ab}}$
}

Biochar is an efficient and cost-effective sorbent for removing contaminants from aqueous environments. In this study, biochar samples derived from rice straw (R) and swine manure (M) pyrolyzed at $400{ }^{\circ} \mathrm{C}(\mathrm{R} 400$ and $\mathrm{M} 400$ ) and $600{ }^{\circ} \mathrm{C}$ (R600 and M600) were used to adsorb tetracycline from an aqueous solution. The adsorption of tetracycline on both types of biochar included multi-step adsorption processes that were well described by the pseudo-second-order kinetics model $\left(R^{2}>0.99\right)$. The adsorption equilibrium of tetracycline on rice straw and swine manure derived biochar was reached after $24 \mathrm{~h}$ and $36 \mathrm{~h}$ respectively. The solution $\mathrm{pH}$ affected the adsorption processes by changing the surface charges of tetracycline and biochar. Adsorption isotherms fitted both the Langmuir and Freundlich models well. The adsorption capacity was higher in biochar derived from rice straw than in biochar derived from swine manure, and increased with increasing pyrolysis temperature. Thermodynamic analysis revealed a spontaneous and endothermic tetracycline adsorption process. The values of the adsorption coefficient $\left(K_{\mathrm{d}}\right)$ were on the order of $10^{3}$ for R600 and $10^{2}-10^{3}$ for the other three types of biochar. These experiments indicate that R600 can be used as an inexpensive adsorbent to remove tetracycline from aqueous solutions, but swine manure derived biochar needs more improvement to be a suitable adsorbent.

\author{
Received 15th February 2018 \\ Accepted 21st April 2018 \\ DOI: $10.1039 / \mathrm{c} 8 \mathrm{ra01454j}$ \\ rsc.li/rsc-advances
}

\section{Introduction}

Tetracyclines are some of the most commonly used veterinary antibiotics and growth promoters in the livestock industry. ${ }^{1}$ However, the majority of tetracyclines cannot be absorbed by the animals to which they are applied. It has been reported that up to $50-80 \%$ of tetracyclines are excreted into the environment with feces and urine in an unchanged form. ${ }^{2}$ These residual tetracyclines accumulate in the aquatic and soil environment through domestic wastewater effluent and agricultural use of the feces of livestock animals. ${ }^{3,4}$ Once in the environment, antibiotics exert adverse effects such as the promotion of antibiotic resistance via gene transfer within pathogenic bacteria, as well as the development of multi-resistant bacterial strains. ${ }^{5}$ Therefore, it is important to develop efficient and cost-effective treatment technologies for the removal of tetracycline.

Adsorption has been confirmed to be a practically feasible and efficient means of controlling tetracycline transport in the environment. ${ }^{6}$ Recent studies have focused on the adsorption of tetracycline by various adsorbents, including natural or

${ }^{a}$ Key Laboratory of Recycling and Eco-treatment of Waste Biomass of Zhejiang Province, Zhejiang University of Science and Technology, Hangzhou 310023, Zhejiang, China. E-mail: fangchengr@163.com

${ }^{b}$ School of Civil Engineering and Architecture, Zhejiang University of Science and Technology, Hangzhou 310023, Zhejiang, China

$\dagger$ Electronic supplementary information (ESI) available. See DOI: $10.1039 / \mathrm{c} 8 \mathrm{ra} 01454 \mathrm{j}$ engineered ones such as soils, ${ }^{7}$ activated carbons, ${ }^{8}$ carbon nanotubes ${ }^{9}$ and graphene oxide. ${ }^{10}$ For example, Ji et al. ${ }^{9}$ found that the adsorption coefficient $\left(K_{\mathrm{d}}\right)$ of single-walled carbon nanotubes for tetracycline adsorption was $10^{3}-10^{4} \mathrm{~L} \mathrm{~kg}^{-1}$. However, these materials are expensive. It has been reported that the cost of carbon nanotubes is $\$ 120-180$ per kilogram. ${ }^{11}$ Therefore, it is necessary to identify lower cost alternatives, especially for use in large scale water treatment facilities. ${ }^{12}$

Biochar, which is a carbon rich solid that is pyrolyzed from various types of waste biomass, is considered to be a promising resource for soil amendments and the treatment of contaminated water. ${ }^{6,13}$ Biochar acts as a kind of efficient and cost-effective sorbent which is capable of removing contaminants including organic or inorganic pollutants from aqueous environments. ${ }^{14}$ Previous studies have revealed the effects of a variety of factors on the adsorption of tetracycline by biochar, including pyrolysis temperature,,$^{15} \mathrm{pH}$ and metal concentration of the solution ${ }^{16}$ and modifications of the biochar using various methods. ${ }^{17}$ For example, Zhang et al. ${ }^{15}$ studied the adsorption capacities of biochar derived from corn straw pyrolyzed at different temperatures $\left(100-600{ }^{\circ} \mathrm{C}\right)$ and found that biochar pyrolyzed at $600{ }^{\circ} \mathrm{C}$ had the highest adsorption affinity. The biomass feedstock of biochar may influence the adsorption capacity of tetracycline because of different biochar characteristics; ${ }^{18}$ however, few studies have been conducted to assess the effects of biochar feedstock on tetracycline adsorption. 
Rice straw and swine manure are two of the most abundant agricultural wastes in China. ${ }^{19,20}$ These residuals have received widespread environmental concern, especially swine manure that contains various antibiotics and antibiotic resistance genes. ${ }^{21,22}$ Converting these low cost, high carbon and abundant residuals into biochar can reduce the adverse environmental effects and produce renewable energy. ${ }^{23}$ There are many reports regarding the adsorption of tetracycline by biochar, but these studies mainly focus on biochar derived from the residue of plants. Until now, little research has involved the adsorption process of biochar from livestock manure, including swine manure. The mechanisms involved in the adsorption process of tetracycline on biochar from swine manure are still not clear. Therefore, our objectives in this study were to: (1) compare the characteristics of biochar derived from rice straw and swine manure; (2) investigate the adsorption capacities of tetracycline on both types of biochar and analyze the mechanisms by which tetracycline and the biochar interact.

\section{Methods and materials}

\subsection{Materials}

The rice straw and fresh swine manure were obtained from cropland and an intensive swine production unit, respectively, in Hangzhou, Zhejiang province, China. Biochar was produced by pyrolyzing air-dried samples at $400{ }^{\circ} \mathrm{C}$ or $600{ }^{\circ} \mathrm{C}$ under oxygen-limited conditions in a muffle furnace. The sample temperature was increased to the target pyrolysis temperature, where it was held for $2 \mathrm{~h}$. The four biochar samples are denoted $\mathrm{R} 400, \mathrm{R} 600$, M400 and M600, where $\mathrm{R}$ and $\mathrm{M}$ are rice straw and swine manure, and 400 and 600 are pyrolysis temperatures of $400{ }^{\circ} \mathrm{C}$ and $600{ }^{\circ} \mathrm{C}$, respectively. Once cool, the biochar samples were ground and passed through a $0.15 \mathrm{~mm}$ sieve.

The sorbate tetracycline $(>97.7 \%, \mathrm{w} / \mathrm{w})$ was obtained from $\mathrm{Dr}$ Ehrenstorfer (Ausberg, Germany) while all other chemicals were analytical grade or better.

\subsection{Biochar characteristics}

Elemental (C, H, O and N) analysis was conducted using an elemental analyzer (Vario MICRO, Elementar, Germany). The Brunauer-Emmett-Teller surface area $\left(S_{\mathrm{BET}}\right)$ and pore structure parameters of the biochar samples were obtained using an Autosorb-IQC gas analyzer (Quantachrome, USA) with $\mathrm{N}_{2}$ physical adsorption at $77 \mathrm{~K}$. Fourier transform infrared (FTIR) spectroscopy (VERTEX 70, BRUKER, Germany) was used to identify functional groups on the biochar surfaces.

\subsection{Adsorption experiments}

The tetracycline adsorption experiments were performed in batch adsorption mode. Methanol was used to prepare a stock solution of tetracycline $\left(100 \mathrm{mg} \mathrm{L}^{-1}\right)$ where the volume percentage of methanol was $<0.1 \%$ to minimize possible cosolvent effects on sorption. ${ }^{9}$ Experiments to investigate the adsorption kinetics of tetracycline onto biochar were performed in a series of $40 \mathrm{~mL}$ brown glass vials by mixing $60 \mathrm{mg}$ of biochar with $20 \mathrm{~mL}$ tetracycline solution. The tetracycline solution contained $0.01 \mathrm{~mol} \mathrm{~L}^{-1} \mathrm{NaNO}_{3}$ and $32 \mathrm{mg} \mathrm{L}^{-1}$ tetracycline. The samples were then shaken on a horizontal shaker at $150 \mathrm{rpm}$ at $25{ }^{\circ} \mathrm{C}$ for $0.5,1,1.5,2,5,8,12,18,24,36,48$, or $60 \mathrm{~h}$. The samples were subsequently centrifuged at $5000 \mathrm{rpm}$ for $10 \mathrm{~min}$. Next, the supernatant was passed through a $0.45 \mu \mathrm{m}$ filter and the concentrations of residual tetracycline were measured using high performance liquid chromatography (e2695, Waters, USA) using a C-18 column and a UV-vis spectrometer (2489, Waters, USA) operating at $355 \mathrm{~nm}$.

The adsorption isotherm experiments were conducted with various initial tetracycline concentrations of 0.5 to $32 \mathrm{mg} \mathrm{L}^{-1}$ at $25^{\circ} \mathrm{C}$. A $20 \mathrm{~mL}$ aqueous solution of $0.01 \mathrm{~mol} \mathrm{~L}{ }^{-1} \mathrm{NaNO}_{3}$ containing tetracycline and $60 \mathrm{mg}$ biochar was added to a $40 \mathrm{~mL}$ brown glass vial that was fitted with a plastic cap. The mixture was shaken at $150 \mathrm{rpm}$ until sorption equilibrium was attained according to adsorption kinetics. The tetracycline concentration of the aqueous solution was determined using the same method as above.

The effect of solution $\mathrm{pH}$ on the adsorption of tetracycline by biochar was investigated in another series of batch experiments using a concentration of tetracycline of $16 \mathrm{mg} \mathrm{L}^{-1}$. The $\mathrm{pH}$ of the tetracycline solution was varied from 2.0 to 11.0. The influence of the adsorption temperature was determined at 15 , 25 and $35{ }^{\circ} \mathrm{C}$ with a concentration of tetracycline of $16 \mathrm{mg} \mathrm{L}^{-1}$. The ratio of biochar and tetracycline solution was 60 $\mathrm{mg}: 20 \mathrm{~mL}$.

In each experiment, control samples (without biochar or without tetracycline) were simultaneously prepared. However, no measurable change was observed for the tetracycline concentrations during the control experiment. All of the adsorption experiments were performed in triplicate.

\subsection{Data analysis}

The amount of tetracycline adsorbed on the biochar at time $t$ $\left(q_{t}, \mathrm{mg} \mathrm{g}^{-1}\right)$ was calculated using eqn (1):

$$
q_{t}=\frac{\left(C_{0}-C_{t}\right) \times V}{m}
$$

where $C_{0}\left(\mathrm{mg} \mathrm{L}^{-1}\right)$ and $C_{t}\left(\mathrm{mg} \mathrm{L}^{-1}\right)$ are the initial tetracycline concentration and tetracycline concentration at $t(\mathrm{~h})$, respectively. Additionally, $m(\mathrm{~g})$ and $V(\mathrm{~L})$ are the mass of biochar and the volume of the reaction solution, respectively.

In the adsorption kinetics experiment, the data were fitted using a pseudo-first-order model (eqn (2)), a pseudo-secondorder model (eqn (3)), and an intra-particle diffusion model (eqn (4)).

$$
\begin{gathered}
q_{t}=q_{\mathrm{e}}\left(1-\mathrm{e}^{-k_{1} t}\right) \\
q_{t}=\frac{k_{2} q_{\mathrm{e}}^{2} t}{1+k q_{\mathrm{e}} t} \\
q_{t}=k_{\mathrm{i}} t^{1 / 2}+I
\end{gathered}
$$

where $k_{1}\left(\mathrm{~h}^{-1}\right)$ and $k_{2}\left(\mathrm{~g} \mathrm{mg}^{-1} \mathrm{~h}^{-1}\right)$ are the rate constants of the pseudo-first-order model and the pseudo-second-order model, respectively, and $k_{\mathrm{i}}\left(\mathrm{mg} \mathrm{g}^{-1} \mathrm{~h}^{-1 / 2}\right)$ is the constant of the intra- 
particle diffusion model. Additionally, $q_{\mathrm{e}}\left(\mathrm{mg} \mathrm{g}^{-1}\right)$ is the sorption capacity at the equilibrium time, and $I$ is the intercept reflecting the extent of the boundary layer thickness. ${ }^{24}$

The Langmuir (eqn (5)), Freundlich (eqn (6)) and Tempkin (eqn (7)) adsorption models were fitted to the data of the adsorption isotherms.

$$
\begin{gathered}
q_{\mathrm{e}}=q_{\mathrm{max}} K_{\mathrm{L}} C_{\mathrm{e}} /\left(1+K_{\mathrm{L}} C_{\mathrm{e}}\right) \\
q_{\mathrm{e}}=K_{\mathrm{f}} C_{\mathrm{e}}{ }^{n} \\
q_{\mathrm{e}}=\frac{R T}{b_{\mathrm{T}}} \ln \left(K_{\mathrm{T}} C_{\mathrm{e}}\right)
\end{gathered}
$$

where $C_{\mathrm{e}}\left(\mathrm{mg} \mathrm{L}^{-1}\right)$ is the tetracycline concentration in the solution phase, $K_{\mathrm{L}}\left(\mathrm{L} \mathrm{mg^{-1 } )}\right.$ is the Langmuir sorption coefficient, $q_{\max }\left(\mathrm{mg} \mathrm{g}^{-1}\right)$ is the sorption capacity and $K_{\mathrm{f}}\left(\mathrm{mg}^{1-n} \mathrm{~L}^{n}\right.$ $\mathrm{g}^{-1}$ ) and $n$ are the sorption and nonlinear coefficients in the Freundlich equation, respectively. Additionally, $k_{\mathrm{T}}\left(\mathrm{L} \mathrm{mg} \mathrm{m}^{-1}\right)$ is the Tempkin constant that corresponds to the maximum binding energy. Moreover, $T(\mathrm{~K})$ and $R\left(8.314 \mathrm{~J} \mathrm{~mol}^{-1} \mathrm{~K}^{-1}\right)$ are the absolute temperature and universal gas constant, respectively, while $b_{\mathrm{T}}$ is obtained after solving the Temkin equation.

\section{Results and discussion}

\subsection{Biochar characteristics}

The chemical compositions of the biochar are shown in Table 1. The carbon $(\mathrm{C})$, oxygen $(\mathrm{O})$ and hydrogen $(\mathrm{H})$ content of rice straw biochar was higher than that of swine manure biochar. As the pyrolysis temperature increased, the content of $\mathrm{C}$ increased in rice straw biochar, while it decreased in swine manure biochar, which was consistent with the available literature. ${ }^{25}$ The $\mathrm{O}$ and $\mathrm{H}$ content of biochar showed a decreasing trend in both types of biochar with increasing pyrolysis temperature. At the same time, the $\mathrm{H} / \mathrm{C}, \mathrm{O} / \mathrm{C}$ and $(\mathrm{O}+\mathrm{N}) / \mathrm{C}$ ratios of the two kinds of biochar decreased with increasing pyrolysis temperature, indicating that high pyrolysis temperature results in more aromatic carbon and less hydrophilicity and polarity. ${ }^{26}$

As the pyrolysis temperature increased, the surface area of the two kinds of biochar increased, especially that of the rice straw biochar which increased from 6.74 to $21.69 \mathrm{~m}^{2} \mathrm{~g}^{-1}$ (Table 1). The high pyrolysis temperature causes the precipitation of volatile matter, which subsequently increases the number of micropores, causing an increase in specific surface area and pore volume. ${ }^{27}$ At the same pyrolysis temperature, the surface area of rice straw biochar was 2.05 times that of swine manure biochar at $600{ }^{\circ} \mathrm{C}$ (Table 1). At the same time, the micropore volume and average pore size of rice straw biochar were also higher than those of swine manure biochar. This might be related to the structure of the raw material. This indicates that the pore structure of rice straw biochar is more developed than that of swine manure biochar.

The FTIR fingerprints are shown in Fig. 1. The absorption between 3200 and $3500 \mathrm{~cm}^{-1}$ corresponded to the stretching vibrations of $-\mathrm{OH},{ }^{25}$ while the peaks at 2922 and $2853 \mathrm{~cm}^{-1}$ indicated an aliphatic $-\mathrm{CH}$ stretching vibration. ${ }^{17}$ A loss of intensity in these peaks was observed in M600 and R600 compared to M400 and R400, respectively, suggesting that $\mathrm{O}$ containing hydroxyl and aliphatic carbon functional groups were transformed at the increased pyrolysis temperature. At the same time, the feedstock influenced the functional groups of the biochar. The swine manure biochar contained more - $\mathrm{OH}$, but less aliphatic $-\mathrm{CH}$ than the rice straw biochar at each pyrolysis temperature. The peak intensities at $1633 \mathrm{~cm}^{-1}$ decreased as pyrolysis temperature increased and were designated as $\mathrm{C}=\mathrm{O}$ and $\mathrm{C}=\mathrm{C}$ stretching. ${ }^{28}$ The bands around 1000 to $1100 \mathrm{~cm}^{-1}$ were associated with $\mathrm{Si}-\mathrm{O}-\mathrm{Si}$ groups, the $\mathrm{P}-\mathrm{O}$ bond of phosphate and the $\mathrm{C}-\mathrm{O}$ bond of carbonate. ${ }^{29}$

\subsection{Adsorption kinetics}

The adsorption kinetics of tetracycline on biochar are shown in Fig. 2. The shapes of the kinetics curves exhibited three stages

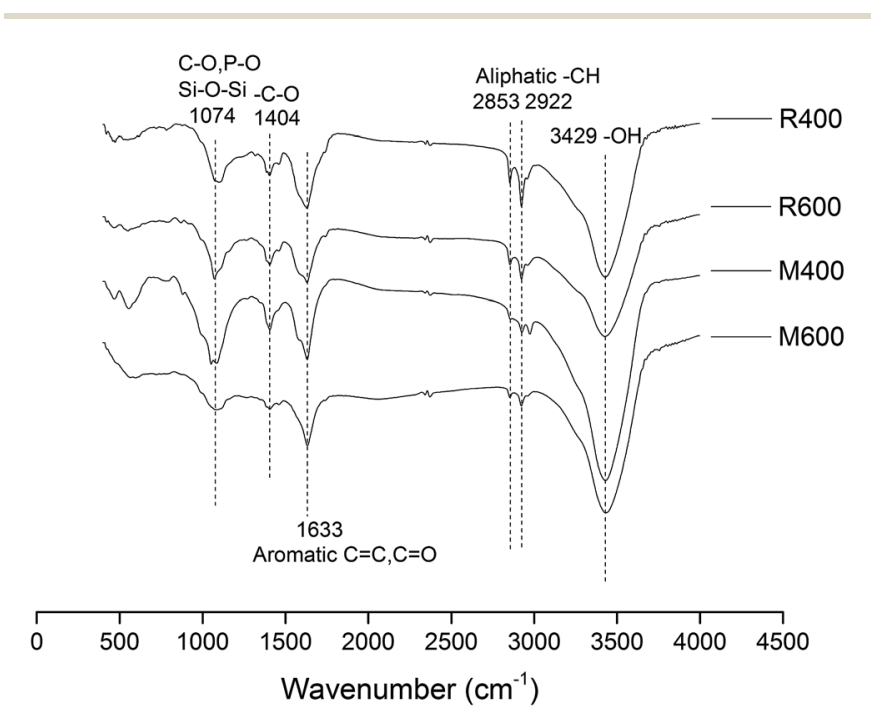

Fig. 1 Fourier transform infrared (FTIR) spectroscopic analysis of

\begin{tabular}{|c|c|c|c|c|c|c|c|c|c|c|}
\hline $\mathrm{BC}$ & $\mathrm{C}^{a}(\%)$ & $\mathrm{N}(\%)$ & $\mathrm{O}(\%)$ & $\mathrm{H}(\%)$ & $\mathrm{O} / \mathrm{C}$ & $\mathrm{H} / \mathrm{C}$ & $(\mathrm{O}+\mathrm{N}) / \mathrm{C}$ & $S_{\mathrm{BET}}\left(\mathrm{m}^{2} \mathrm{~g}^{-1}\right)$ & $V_{\text {tot }}\left(\mathrm{cm}^{3} \mathrm{~g}^{-1}\right)$ & Pore width $(\mathrm{nm})$ \\
\hline $\mathrm{R} 400$ & 50.02 & 1.62 & 17.36 & 3.52 & 0.35 & 0.07 & 0.40 & 6.74 & 0.019 & 20.63 \\
\hline R600 & 55.33 & 1.15 & 11.21 & 1.67 & 0.20 & 0.03 & 0.22 & 21.69 & 0.054 & 17.04 \\
\hline M400 & 35.68 & 2.56 & 10.94 & 2.26 & 0.31 & 0.06 & 0.37 & 5.17 & 0.013 & 16.38 \\
\hline M600 & 31.27 & 1.84 & 7.85 & 1.70 & 0.25 & 0.05 & 0.31 & 10.56 & 0.044 & 12.36 \\
\hline
\end{tabular}
biochar.

Table 1 Chemical composition and pore structure of biochar (BC).

${ }^{a}$ The content of $\mathrm{C}, \mathrm{N}, \mathrm{O}$ and $\mathrm{H}$ elements in the biochar. 

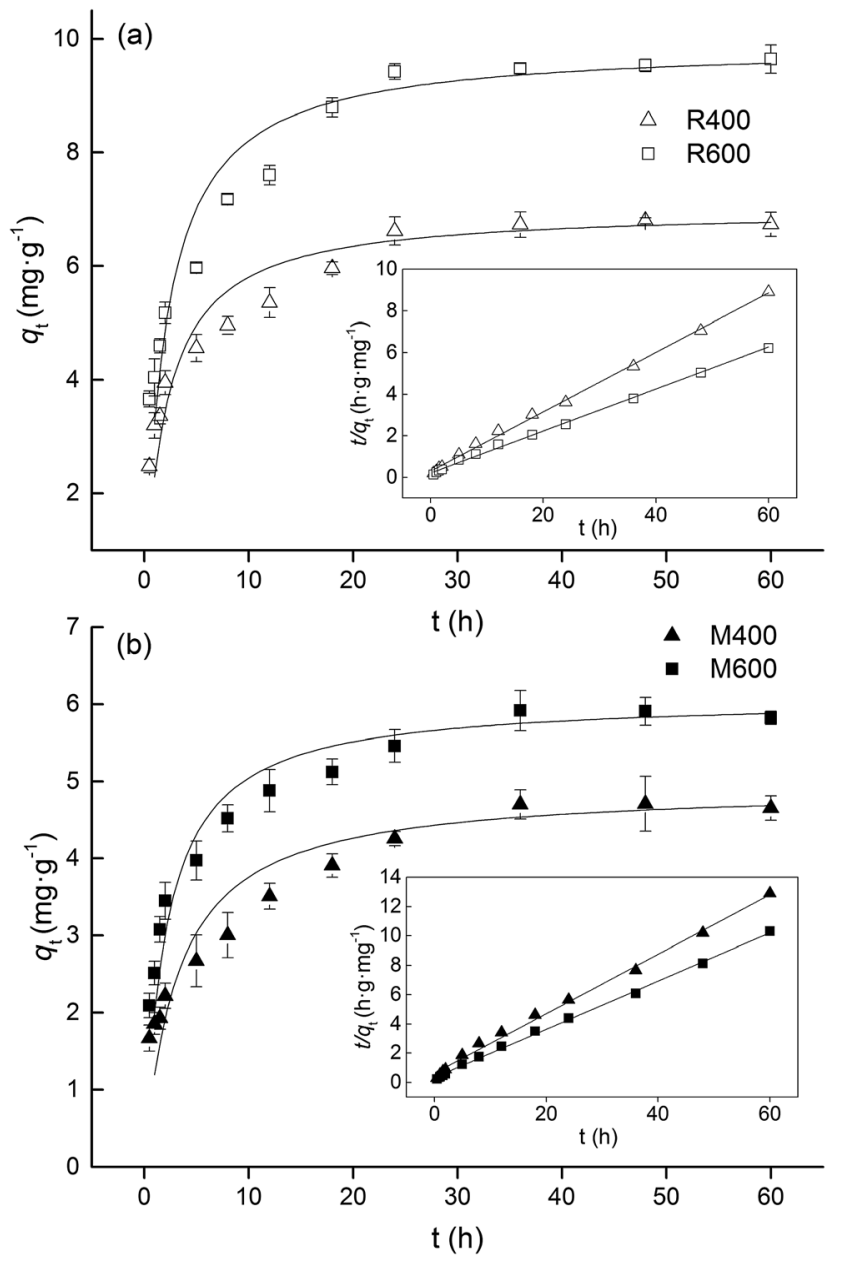

Fig. 2 Adsorption kinetics (pseudo-second-order model) of tetracycline on (a) rice straw derived biochar and (b) swine manure derived biochar. The inset is the linear plot of the pseudo-second-order model fit. Error bars indicate the SD.

in the adsorption process, a fast initial adsorption, a slow adsorption and a stable stage. In the fast adsorption process, about $70 \%$ of the adsorption capacity occurred within the first $8 \mathrm{~h}$. A possible reason is that the high concentration of tetracycline at the interface between the biochar and the solution facilitates a great mass transfer driving force ${ }^{12}$ which causes tetracycline to rapidly occupy the adsorption sites of the biochar surface. For rice straw biochar, no significant change was found in $q_{t}$ from $24 \mathrm{~h}$ to $60 \mathrm{~h}$ (Tukey test, $p>0.05$ ), indicating that adsorption equilibrium was reached after $24 \mathrm{~h}$. Jia et al. ${ }^{\mathbf{1 6}}$ showed that the adsorption equilibrium time of oxytetracycline was $24 \mathrm{~h}$, which is consistent with the result of our study. However, adsorption equilibrium was reached after $36 \mathrm{~h}$ for swine manure biochar.

Pseudo-first-order and pseudo-second-order models were used to analyze the experimental data. The adsorption kinetics parameters are shown in Table 2. The experimental data fitted well with the pseudo-second-order kinetics model $\left(R^{2}>0.99\right)$ (Fig. 2, Table 2), which indicated that the adsorption of tetracycline by all biochar involved chemical adsorption processes. ${ }^{\mathbf{1 6}}$ This is in line with the results of many other studies. ${ }^{17,30,31}$ At the same time, the values of $q_{\mathrm{e}}$ calculated based on the pseudosecond-order model were similar to the experimental values. The values of $q_{\mathrm{e}}$ of the rice straw biochar were higher than those of the swine manure biochar, and increased with increasing pyrolysis temperature.

An intra-particle diffusion model was applied to determine the diffusion mechanisms and identify the possible ratelimiting step of the adsorption process. ${ }^{32}$ As shown in Fig. 3, the plots of $q_{t}$ against $t^{1 / 2}$ exhibited multi-linearity including three linear portions for both types of biochar (with the exception of M400), indicating that there were multiple steps in the adsorption process. Previous studies have shown that the tetracycline adsorption processes on biochar or activated carbon consisted of three stages, external diffusion or film diffusion, gradual adsorption and final equilibrium. ${ }^{33,34}$ In this study, the first stage of the plots with a relatively high slope was attributed to external diffusion, in which the tetracycline migrated from the bulk solution to the external surface of the biochar. The second stage presented a relatively high adsorption rate and indicated the gradual adsorption stage. In this stage, tetracycline underwent molecular diffusion from the external surface to the adsorption sites of the biochar, and was adsorbed at the active sites. The last stage was a final equilibrium stage in which the adsorption rate was equal to the desorption rate. This might be due to the decrease in available surface area of the biochar, the enhanced electrostatic repulsion between tetracycline molecules adsorbed on the surface of the biochar and those in the solution or the extremely low concentration of adsorbate remaining in the solution.

It has been reported that, if the fitted plots of the intraparticle diffusion model were linear and passed through the origin, the rate-limiting step of the adsorption processes is intra-particle diffusion. ${ }^{35}$ However, no linear fitted plots passed through the origin in this study, which is inconsistent with the results of previous studies. ${ }^{31,33,34}$ Intra-particle diffusion was not

Table 2 Pseudo-first-order and pseudo-second-order parameters for the adsorption of tetracycline on biochar.

\begin{tabular}{|c|c|c|c|c|c|c|}
\hline Biochar & \multicolumn{3}{|c|}{ Pseudo-first-order } & \multicolumn{3}{|c|}{ Pseudo-second-order } \\
\hline R600 & 0.069 & 4.441 & 0.847 & 0.049 & 9.898 & 0.998 \\
\hline M400 & 0.110 & 3.507 & 0.789 & 0.065 & 4.930 & 0.995 \\
\hline M600 & 0.092 & 3.485 & 0.959 & 0.080 & 6.077 & 0.998 \\
\hline
\end{tabular}



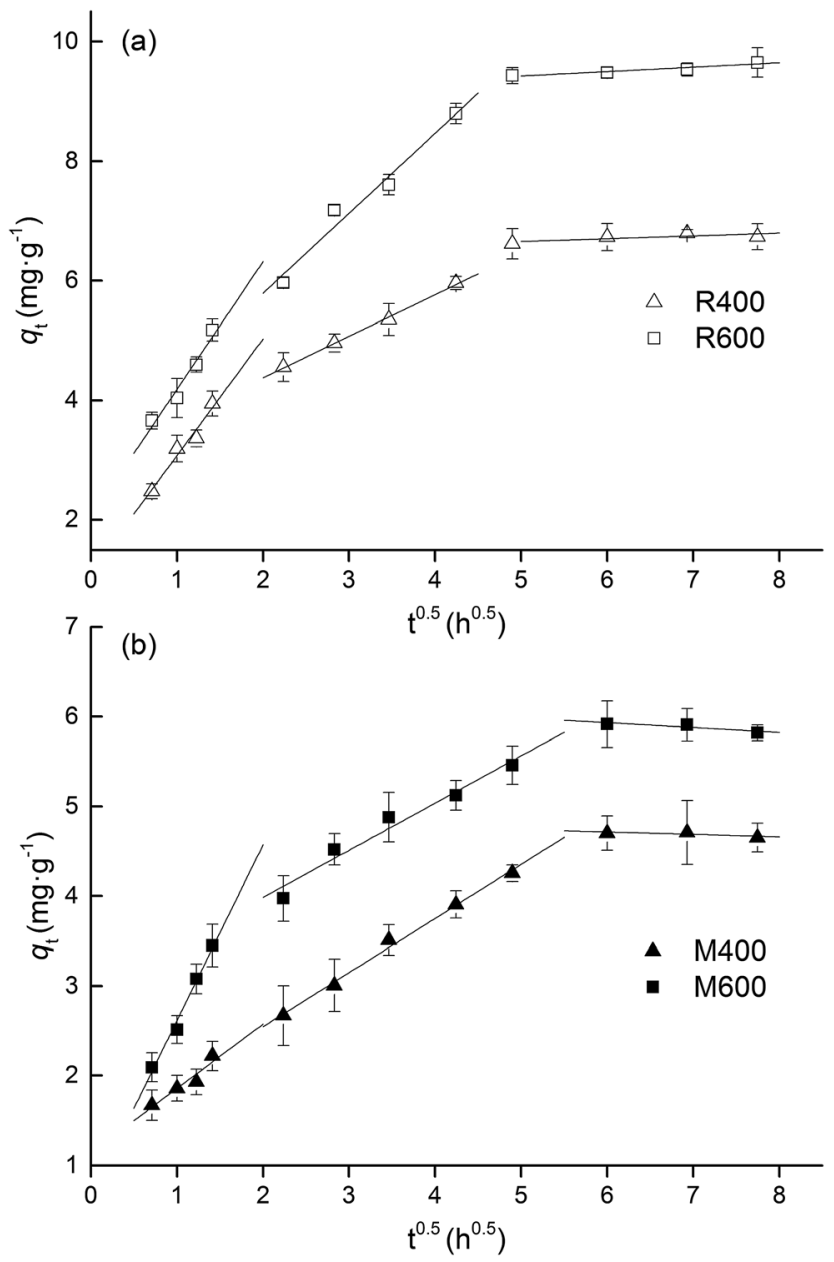

Fig. 3 Intra-particle diffusion model for adsorption of tetracycline on (a) rice straw derived biochar and (b) swine manure derived biochar. Error bars indicate the SD.

the exclusive rate determining step of the tetracycline adsorption processes on biochar. ${ }^{24}$ There might be other processes involved in adsorption, including initial external mass transfer or chemical reactions. ${ }^{36}$

\subsection{The impact of $\mathrm{pH}$}

As shown in Fig. 4, the solution $\mathrm{pH}$ greatly affected the adsorption capacities of the biochar. As pH increased, adsorption capacity initially increased but then fell, with the maximum observed around $\mathrm{pH}$ 5.0. The $\mathrm{pH}$ of the solution changes the surface charges of tetracycline and biochar, and thus has an influence on the adsorption processes. ${ }^{\mathbf{1 6 , 1 7}}$ As an amphoteric molecule, tetracycline has three values of $\mathrm{p} K_{\mathrm{a}}(3.32,7.78$, and 9.58) and presents four kinds of species under different $\mathrm{pH}$ conditions. ${ }^{37}$ The dominant one is cationic tetracycline (TC+00) with $\mathrm{pH}<3.32$, zwitterionic tetracycline $(\mathrm{TC}+-0)$ when the $\mathrm{pH}$ ranged from 3.32 to 7.78 and amination anionic tetracycline (TC+--) or bivalent anionic tetracycline (TC0--) with $\mathrm{pH}>$ 7.78 (Fig. 5). It has been reported that the isoelectric points of all the biochar in this study were between 3 and $4 .^{25,38}$ When the $\mathrm{pH}$ was outside of the range of 3.32-7.78, electrostatic repulsion

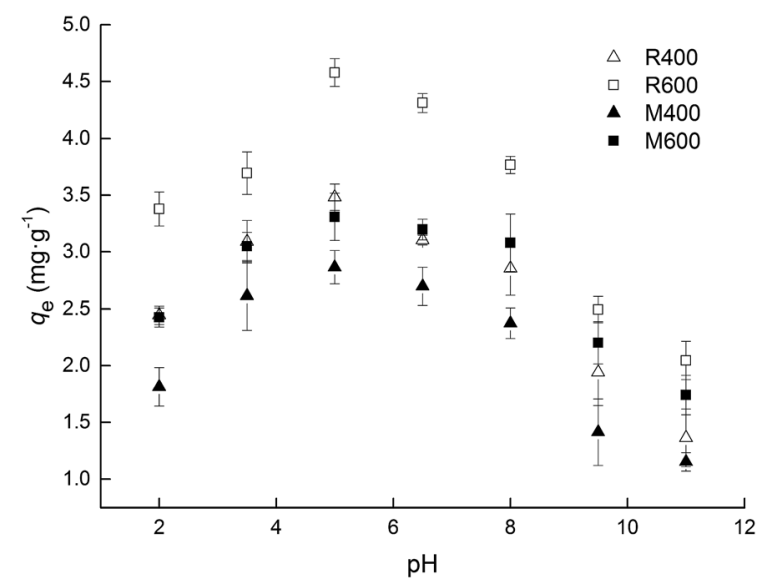

Fig. 4 Effect of pH on adsorption capacity for tetracycline sorption on biochar. Error bars indicate the SD.

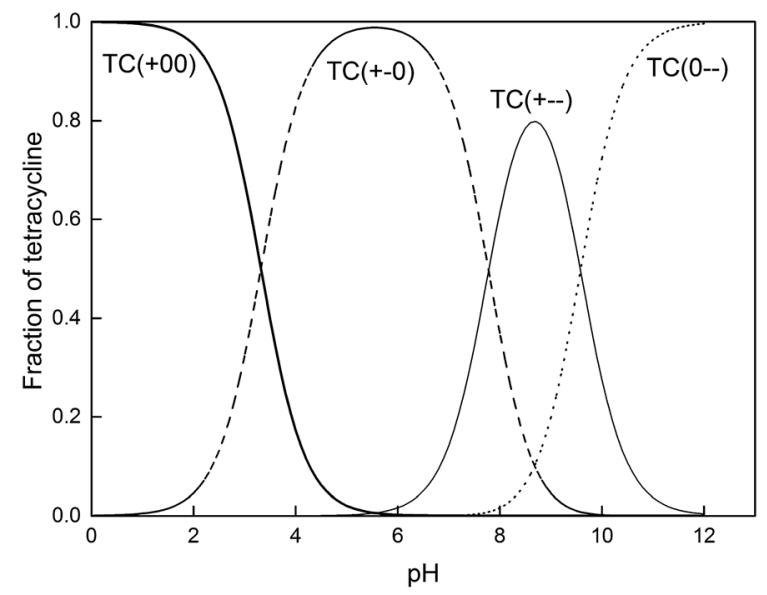

Fig. 5 Tetracycline species distribution at different $\mathrm{pH}$ values. $\mathrm{TC}(+00), \mathrm{TC}(+-0), \mathrm{TC}(+--)$ and $\mathrm{TC}\left(\mathrm{O}_{--}\right)$are cationic tetracycline, zwitterionic tetracycline, amination anionic tetracycline and bivalent anionic tetracycline, respectively.

occurred because the charge on the biochar surface and the tetracycline molecules was the same. Thus, relatively higher adsorption capacities were observed when the solution $\mathrm{pH}$ was in a range of 3.5-8.0. In addition, the biochar surface was electron deficient because the biochar was positively charged when the $\mathrm{pH}$ was 2 . There were relatively weak $\pi-\pi$ EDA interactions between biochar and tetracycline, which resulted in decreased adsorption capacity.

To study the contribution of different tetracycline species to the adsorption process, the adsorption coefficient $K_{\mathrm{d}}$ (eqn (8)) and empirical model ${ }^{39}$ (eqn (9)) were employed in this study.

$$
K_{\mathrm{d}}=q_{\mathrm{e}} / C_{\mathrm{e}}
$$

$K_{\mathrm{d}}=K_{\mathrm{d}}^{+00} \times f^{+00}+K_{\mathrm{d}}^{+-0} \times f^{+-0}+K_{\mathrm{d}}^{+--} \times f^{+--}+K_{\mathrm{d}}^{0--} \times f^{0--}$

where $K_{\mathrm{d}} \quad\left(\mathrm{L} \quad \mathrm{kg}^{-1}\right)$ is the adsorption coefficient. $K_{\mathrm{d}}^{+00}, K_{\mathrm{d}}^{+-0}, K_{\mathrm{d}}^{+--}$and $K_{\mathrm{d}}^{0--}$ are the respective adsorption 
coefficients of tetracycline species as fitting parameters. $f^{+00}$, $f^{+-0}, f^{+--}$and $f^{0--}$ are the fractions of cationic, zwitterionic, amination anionic and bivalent anionic species, respectively, in the solution.

The $K_{\mathrm{d}}$ values calculated based on eqn (8) are shown in Fig. S1 (ESI), $\dagger$ and exhibited similar trends to the adsorption capacities under different $\mathrm{pH}$ conditions. The $K_{\mathrm{d}}$ data showed a good fit to eqn (9) as the $R^{2}$ coefficients were higher than 0.920 (Table 3). In general, the order of the respective adsorption coefficients of the four tetracycline species was as follows: $K_{\mathrm{d}}^{+-0}>K_{\mathrm{d}}^{+00}>K_{\mathrm{d}}^{+--}>K_{\mathrm{d}}^{0--}$. This indicates that the zwitterionic species has the highest adsorption affinity of all of the biochar. The contribution of each tetracycline species to the adsorption capacity was calculated by weighting the fraction with the corresponding adsorption coefficients (Fig. S2, ESI $\dagger$ ). It was found that the zwitterionic tetracycline contributed more than $60 \%$ to the tetracycline adsorption when the $\mathrm{pH}$ ranged from 3.5 to 8.0, and even higher than $85 \%$ in the $\mathrm{pH}$ range of 5.0-6.5. For zwitterionic species, the electrostatic interaction may have limited influence on the adsorption. Zwitterionic species can easily interact with the negatively charged biochar surface because of the $\pi-\pi$ EDA interactions. The negative tetracycline species also contributed more than $50 \%$ to the tetracycline adsorption on negatively charged biochar when the $\mathrm{pH}$ was above 8.0. This may be attributed to a negative charge assisted $\mathrm{H}$ bond (-(CAHB)) between the negative tetracycline species and surface carboxylate on the biochar. ${ }^{40}$

\subsection{Adsorption isotherms}

The adsorption equilibrium isotherms were evaluated using adsorption isotherm models such as the Freundlich, Langmuir and Tempkin models. As shown in Fig. 6, the experimental data were highly correlated with both the Freundlich and Langmuir models with coefficients $\left(R^{2}\right)$ higher than 0.966 (Table 4). However, the equilibrium data deviated from the Temkin model, with low correlation coefficients $\left(R^{2}\right)$ that ranged from 0.755 to 0.877 . The values of $n$ were Freundlich constants representing the adsorption intensity. The $n$ values were less than 1, implying that the adsorption was a favorable and concentration-dependent process. The trend shown by the $q_{\max }$ values in the Langmuir model was an increase with pyrolysis temperature, which is consistent with the results of previous studies. ${ }^{15,31}$ At the same time, the values of $q_{\max }$ were higher in rice-straw biochar than swine manure biochar, which reflected the relatively high adsorption capacity of rice straw biochar. Based on the Langmuir model, the maximum adsorption
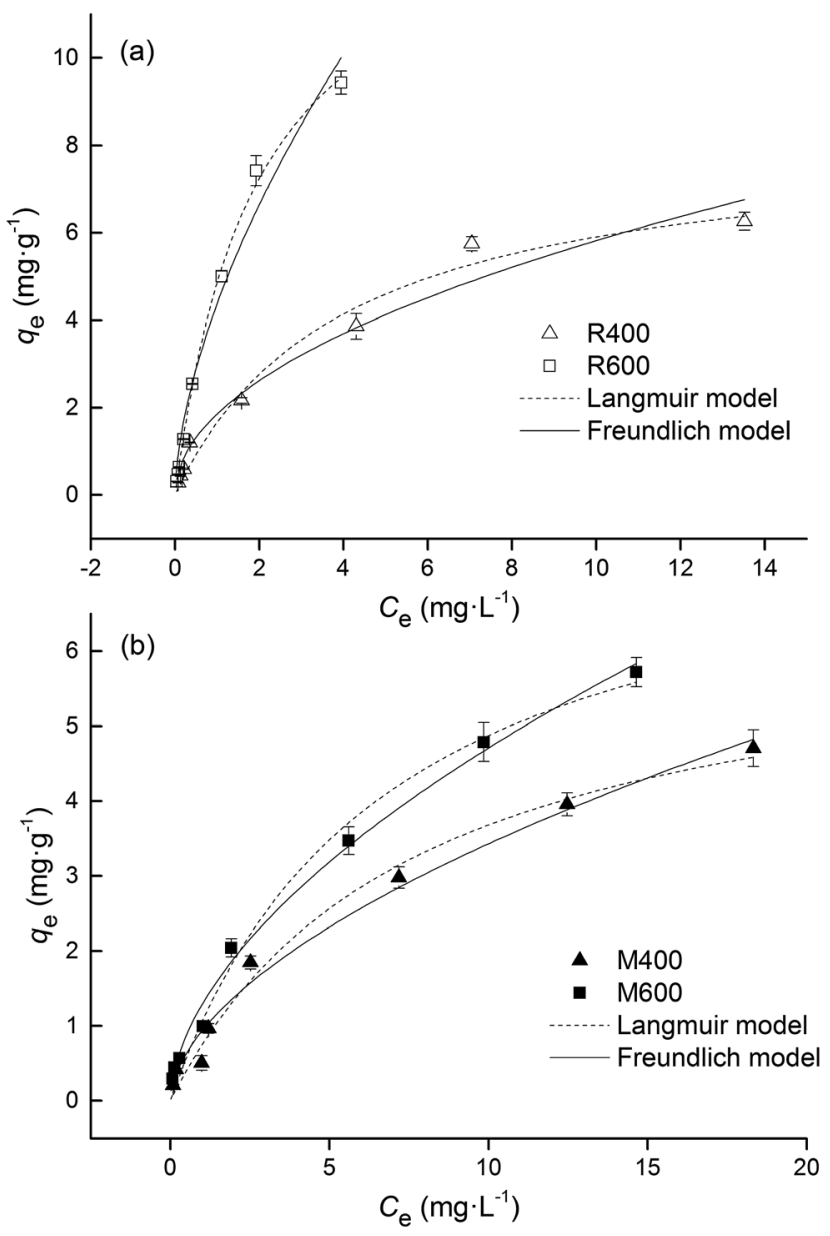

Fig. 6 Adsorption isotherms for the adsorption of tetracycline on (a) rice straw derived biochar and (b) swine manure derived biochar. Error bars indicate the SD.

capacities of biochar from rice straw and swine manure were 13.27 and $8.14 \mathrm{mg} \mathrm{g}^{-1}$ respectively.

The Freundlich model is an empirical model that represents multilayer adsorption on heterogeneous surfaces. The Langmuir model is an ideal model that is based on a perfect adsorbent surface and assumes a monomolecular layer adsorption. In this study, both the Freundlich and the Langmuir models fitted the adsorption data well, indicating the sorption of tetracycline on both types of biochar was affected by multiple mechanisms. Similar results were also found in other relevant studies. ${ }^{17,30}$

The adsorption of tetracycline from the solution onto the biochar involved physical and chemical adsorption processes.

Table 3 Calculated adsorption coefficients for the four tetracycline species at $\mathrm{pH}$ 2.0-11.0.

\begin{tabular}{llcrr}
\hline Biochar & $K_{\mathrm{d}}^{+00}\left(\mathrm{~L} \mathrm{~kg}^{-1}\right)$ & $K_{\mathrm{d}}^{+-0}\left(\mathrm{~L} \mathrm{~kg}^{-1}\right)$ & $K_{\mathrm{d}}^{+--}\left(\mathrm{L} \mathrm{kg}^{-1}\right)$ & $K_{\mathrm{d}}^{0--}\left(\mathrm{L} \mathrm{kg}^{-1}\right)$ \\
\hline R400 & 285.64 & 568.37 & 236.95 & 110.25 \\
R600 & 435.49 & 1700.02 & 209.14 & 231.14 \\
M400 & 182.41 & 384.22 & 161.45 & 83.85 \\
M600 & 285.63 & 537.79 & 274.01 & 0.971 \\
& & & 159.87
\end{tabular}


Table 4 Freundlich, Langmuir and Temkin model parameters for tetracycline adsorption on biochar.

\begin{tabular}{|c|c|c|c|c|c|c|c|c|c|}
\hline Biochar & \multicolumn{3}{|l|}{ Freundlich model } & \multicolumn{3}{|c|}{ Langmuir model } & \multicolumn{3}{|c|}{ Temkin model } \\
\hline R600 & 4.376 & 0.602 & 0.976 & 14.185 & 0.521 & 0.997 & 15.806 & 1.234 & 0.854 \\
\hline M400 & 0.936 & 0.564 & 0.984 & 6.513 & 0.130 & 0.985 & 5.886 & 2.952 & 0.837 \\
\hline M600 & 1.288 & 0.563 & 0.994 & 8.125 & 0.150 & 0.988 & 8.619 & 2.519 & 0.755 \\
\hline
\end{tabular}

The biochar surface area is an important factor. ${ }^{17,41,42}$ In this study, the surface areas $\left(S_{\mathrm{BET}}\right)$ of the biochar samples were significantly positively correlated with the $q_{\max }$ values in the Langmuir model (Table 5). The relatively higher adsorption capacity of rice straw biochar resulted from its relatively high surface area compared to swine manure biochar.

Moreover, several adsorption mechanisms such as $\pi-\pi$ EDA interactions, hydrogen bonding and electrostatic interactions (cation and anion attractions) may be involved in the adsorption of tetracycline onto various adsorbents. Electrostatic interactions (cation and anion attractions) is one of the main mechanisms controlling tetracycline adsorption onto soil. ${ }^{7}$ The Temkin model indicates chemical adsorption mediated by strong electrostatic interactions, ${ }^{\mathbf{4 3}}$ but the adsorption data was poorly correlated with the Temkin model (Table 4) in this study. Therefore, it is unlikely that electrostatic interactions play a dominant role in tetracycline adsorption on biochar. Based on FTIR analysis, more O-containing functional groups which could serve as H-bond acceptors were detected on swine manure biochar and on biochar generated at a lower pyrolysis temperature. However, the adsorption capacities of the swine manure biochar were lower than those of the rice straw biochar. Therefore, the hydrogen bond interaction also might not be a dominant mechanism. $\pi-\pi$ EDA interactions contribute to the adsorption on biochar. ${ }^{16,44}$ The conjugated enone structure of the tetracycline molecule acts as a $\pi$-electron-acceptor because of the strong electron-withdrawing ability of the ketone group. ${ }^{9}$ The graphite-like structure of biochar acts as a $\pi$ electron-donor. ${ }^{17}$

\subsection{Thermodynamic analysis}

To gain insight into the impact of temperature on the adsorption processes, eqn (10)-(12) were used to calculate three thermodynamic parameters including the standard Gibbs free energy $(\Delta G)$, enthalpy $(\Delta H)$ and entropy $(\Delta S)$ :

$$
\Delta G=-R T \ln K_{\mathrm{d}}
$$

$$
\begin{gathered}
\Delta G=\Delta H-T \Delta S \\
\ln K_{\mathrm{d}}=-\Delta H / R T+\Delta S / R
\end{gathered}
$$

where $T(\mathrm{~K})$ is the absolute temperature and $R$ (8.314 $\mathrm{J} \mathrm{mol}^{-1} \mathrm{~K}^{-1}$ ) is the universal gas constant.

Fig. S3 (ESI) $\dagger$ showed the relationship between $\ln K_{\mathrm{d}}$ and $1 / T$. The $\Delta G$ values were calculated from $\ln K_{\mathrm{d}}$. Negative $\Delta G$ values were found for all samples (Table 6), which implied, in agreement with previous studies, ${ }^{\mathbf{1 2 2 4}}$ that the sorption of tetracycline on biochar was thermodynamically favorable and spontaneous. At the same time, the $\Delta G$ values increased with adsorption temperature, which implied that the adsorption process was less thermodynamically favorable at lower temperatures.

The values of $\Delta H$ for the biochar ranged from 10.94 to $67.89 \mathrm{~kJ} \mathrm{~mol}^{-1}$ (Table 6), which implied that the adsorption process was endothermic and more favorable at higher temperatures. At the same time, the values of $\Delta H$ for the rice straw biochar were higher than those for the swine manure biochar. The more energy the tetracycline molecules acquire, the larger the number of them that interact with the active sites on the surface of the biochar, which might result in the relatively high adsorption capacities of the rice straw biochar. The positive $\Delta S$ values revealed an increase in randomness at the biochar/tetracycline interface during the adsorption process, which suggested that the adsorption process favors sorption

Table 6 Thermodynamic parameters for tetracycline sorption on biochar with an initial concentration of tetracycline of $16 \mathrm{mg} \mathrm{L}^{-1}$

\begin{tabular}{llllllll}
\hline & & & \multicolumn{4}{c}{$\Delta G\left(\mathrm{~kJ} \mathrm{~mol}{ }^{-1}\right)$} & \\
\cline { 5 - 6 } Biochar & $\begin{array}{l}\Delta H \\
\left(\mathrm{~kJ} \mathrm{~mol}^{-1}\right)\end{array}$ & $\begin{array}{l}\Delta S \\
\left(\mathrm{~J} \mathrm{~mol}^{-1} \mathrm{~K}^{-1}\right)\end{array}$ & $15{ }^{\circ} \mathrm{C}$ & $25{ }^{\circ} \mathrm{C}$ & $35{ }^{\circ} \mathrm{C}$ & $R^{2}$ \\
\hline R400 & 35.30 & 176.02 & -15.46 & -17.02 & -18.93 & 0.995 \\
R600 & 67.89 & 297.70 & -17.84 & -20.84 & -23.68 & 0.998 \\
M400 & 10.94 & 87.00 & -14.14 & -14.94 & -15.86 & 0.992 \\
M600 & 19.66 & 120.26 & -15.09 & -15.93 & -17.47 & 0.919
\end{tabular}

Table 5 Pearson's linear correlation coefficients between biochar characteristics and the $q_{\max }$ values in the Langmuir model.

\begin{tabular}{lllllllllll}
\hline & $\mathrm{C}^{b}$ & $\mathrm{~N}$ & $\mathrm{O}$ & $\mathrm{H}$ & $\mathrm{O} / \mathrm{C}$ & $\mathrm{H} / \mathrm{C}$ & $(\mathrm{O}+\mathrm{N}) / \mathrm{C}$ & $S_{\mathrm{BET}}{ }^{c}$ & $V_{\text {tot }}$ & Pore width \\
\hline$q_{\max }$ & 0.752 & -0.867 & -0.042 & -0.405 & -0.768 & -0.847 & -0.871 & $0.975^{a}$ & 0.806 & 0.102
\end{tabular}

${ }^{a}$ Correlation is significant at the 0.05 level (2-tailed). ${ }^{b}$ The content of C, N, O and $\mathrm{H}$ elements in the biochar. ${ }^{c}$ The $S_{\mathrm{BET}}$ and $V_{\text {tot }}$ represent the Brunauer-Emmett-Teller surface area and total pore volume respectively. 
stability. ${ }^{45}$ The net positive entropy of tetracycline adsorption may be caused by the positive entropy change induced by the changes of biochar surface numerically exceeding the negative entropy change due to a loss of freedom of the tetracycline. ${ }^{46}$

\subsection{Adsorption affinity}

The $K_{\mathrm{d}}$ values for both types of biochar at experimental tetracycline concentrations are shown in Fig. 7. Larger $K_{\mathrm{d}}$ values were found for rice straw biochar at both pyrolysis temperatures and for biochar pyrolyzed at high temperature, which was consistent with the results calculated from the Langmuir model. Meanwhile, the adsorption coefficients tended to decrease with increasing tetracycline concentration. These findings indicated that the adsorption affinity between tetracycline and biochar was concentration dependent, and was higher at lower concentrations.

$K_{\mathrm{d}}$ is a suitable index for comparing the adsorption capacity of different adsorbents to ensure a consistent comparison. ${ }^{47}$ In this study, the $K_{\mathrm{d}}$ values were in the order of $10^{3}$ for R600, while they ranged from $10^{2}$ to $10^{3}$ for the other three types of biochar. When compared with previous studies, the $K_{\mathrm{d}}$ values of other carbon-based materials including SWNT, MWNT, AC and graphite surpassed $10^{3} \mathrm{~L} \mathrm{~kg}^{-1}$, and reached $10^{4}-10^{6} \mathrm{~L} \mathrm{~kg}^{-1}$ for SWNT. ${ }^{9}$ However, for various natural adsorbents, the $K_{\mathrm{d}}$ values were $10^{2}-10^{3} \mathrm{~L} \mathrm{~kg}^{-1}$ for soils and clay minerals, ${ }^{48,49}$ which were lower than that of R600 and similar to that of the other three types of biochar investigated in this study. Previous studies showed that biochar could efficiently remove tetracycline from aqueous solutions. ${ }^{17,42}$ Wang et al. ${ }^{42}$ found that rice straw biochar pyrolyzed at $700{ }^{\circ} \mathrm{C}$ exhibited relatively high removal efficiencies $(92.8-96.7 \%)$ at a range of initial tetracycline concentrations $\left(0.5-32 \mathrm{mg} \mathrm{L}^{-1}\right)$. In this study, we also found that R600 presented a relatively high adsorption affinity for tetracycline compared to the natural adsorbents, especially at low initial tetracycline concentrations. Therefore, R600 can be used as an attractive adsorbent to remove tetracycline from aqueous solutions because of its low cost.

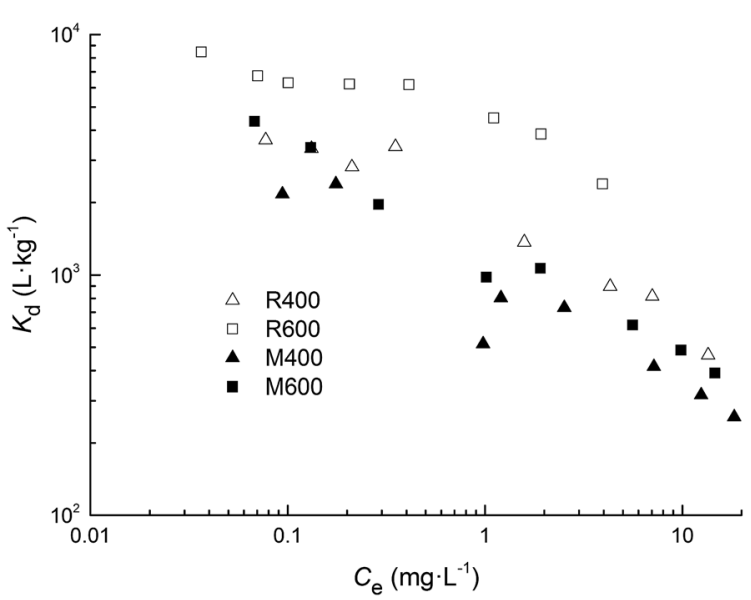

Fig. 7 Values of the adsorption coefficient $\left(K_{d}\right)$ for the sorption of tetracycline on biochar.

\section{Conclusions}

The adsorption equilibrium of tetracycline on rice straw and swine manure biochar was reached after $24 \mathrm{~h}$ and $36 \mathrm{~h}$, respectively. The solution $\mathrm{pH}$ had an influence on the adsorption processes. Relatively higher adsorption capacity could be observed and the zwitterionic tetracycline species contributed more than $60 \%$ to the tetracycline adsorption when the solution $\mathrm{pH}$ ranged from 3.5 to 7.5. The thermodynamic analysis showed that the tetracycline adsorption process was spontaneous and endothermic. The adsorption capacity was higher for biochar from rice straw than for that from swine manure, and increased with increasing pyrolysis temperature. The value of $K_{\mathrm{d}}$ also showed a similar trend. Overall, R600 can be used as an attractive adsorbent to remove tetracycline from aqueous solutions.

\section{Conflicts of interest}

There are no conflicts of interest to declare.

\section{Acknowledgements}

We are grateful to the Innovative Team Foundation of Zhejiang Province (No. 2013TD12), the Public Welfare Technology Application Research Project of Zhejiang Province (No. 2016C33102, No. 2016C33101, No. 2015C33301) and the Zhejiang Provincial Natural Science Foundation of China (No. LY16E080007).

\section{References}

1 Q.-Q. Zhang, G.-G. Ying, C.-G. Pan, Y.-S. Liu and J.-L. Zhao, Environ. Sci. Technol., 2015, 49, 6772-6782.

2 A. K. Sarmah, M. T. Meyer and A. B. Boxall, Chemosphere, 2006, 65, 725-759.

3 Y. Luo, L. Xu, M. Rysz, Y. Wang, H. Zhang and P. J. Alvarez, Environ. Sci. Technol., 2011, 45, 1827-1833.

4 X. Huang, C. Liu, K. Li, F. Liu, D. Liao, L. Liu, G. Zhu and J. Liao, Environ. Sci. Pollut. Res., 2013, 20, 9066-9074.

5 C. W. Knapp, J. Dolfing, P. A. Ehlert and D. W. Graham, Environ. Sci. Technol., 2009, 44, 580-587.

6 M. Ahmad, A. U. Rajapaksha, J. E. Lim, M. Zhang, N. Bolan, D. Mohan, M. Vithanage, S. S. Lee and Y. S. Ok, Chemosphere, 2014, 99, 19-33.

7 S. A. Sassman and L. S. Lee, Environ. Sci. Technol., 2005, 39, 7452-7459.

8 H. Sayğıllı and F. Güzel, Ecotoxicol. Environ. Saf., 2016, 131, 22-29.

9 L. Ji, W. Chen, L. Duan and D. Zhu, Environ. Sci. Technol, 2009, 43, 2322-2327.

10 E. E. Ghadim, F. Manouchehri, G. Soleimani, H. Hosseini, S. Kimiagar and S. Nafisi, PLoS One, 2013, 8, e79254.

11 P. Liao, Z. Zhan, J. Dai, X. Wu, W. Zhang, K. Wang and S. Yuan, Chem. Eng. J., 2013, 228, 496-505.

12 Y. Chen, F. Wang, L. Duan, H. Yang and J. Gao, J. Mol. Liq., 2016, 222, 487-494. 
13 B. Singh, B. P. Singh and A. L. Cowie, Soil Res., 2010, 48, 516525.

14 X. Tan, Y. Liu, G. Zeng, X. Wang, X. Hu, Y. Gu and Z. Yang, Chemosphere, 2015, 125, 70-85.

15 G. Zhang, X. Liu, K. Sun, F. He, Y. Zhao and C. Lin, J. Environ. Qual., 2012, 41, 1906-1915.

16 M. Jia, F. Wang, Y. Bian, X. Jin, Y. Song, F. O. Kengara, R. Xu and X. Jiang, Bioresour. Technol., 2013, 136, 87-93.

17 P. Liu, W.-J. Liu, H. Jiang, J.-J. Chen, W.-W. Li and H.-Q. Yu, Bioresour. Technol., 2012, 121, 235-240.

18 L. Zhao, X. Cao, O. Mašek and A. Zimmerman, J. Hazard. Mater., 2013, 256, 1-9.

19 J. Wu, Y.-y. Hu, S.-f. Wang, Z.-p. Cao, H.-z. Li, X.-M. Fu, K.-j. Wang and J.-e. Zuo, Waste Manag., 2017, 62, 69-75.

20 Z. Lei, J. Chen, Z. Zhang and N. Sugiura, Bioresour. Technol., 2010, 101, 4343-4348.

21 Y.-G. Zhu, T. A. Johnson, J.-Q. Su, M. Qiao, G.-X. Guo, R. D. Stedtfeld, S. A. Hashsham and J. M. Tiedje, Proc. Natl. Acad. Sci. U. S. A., 2013, 110, 3435-3440.

22 L. Zhao, Y. H. Dong and H. Wang, Sci. Total Environ., 2010, 408, 1069-1075.

23 K. S. Ro, K. B. Cantrell and P. G. Hunt, Ind. Eng. Chem. Res., 2010, 49, 10125-10131.

24 Y. Chao, W. Zhu, B. Yan, Y. Lin, S. Xun, H. Ji, X. Wu, H. Li and C. Han, J. Appl. Polym. Sci., 2014, 131, 1-8.

25 J. Meng, X. Feng, Z. Dai, X. Liu, J. Wu and J. Xu, Environ. Sci. Pollut. Res., 2014, 21, 7035-7046.

26 Y. Chun, G. Sheng, C. T. Chiou and B. Xing, Environ. Sci. Technol., 2004, 38, 4649-4655.

27 J. W. Lee, M. Kidder, B. R. Evans, S. Paik, A. Buchanan III, C. T. Garten and R. C. Brown, Environ. Sci. Technol., 2010, 44, 7970-7974.

28 M. Keiluweit, P. S. Nico, M. G. Johnson and M. Kleber, Environ. Sci. Technol., 2010, 44, 1247-1253.

29 Z. Dai, J. Meng, Q. Shi, B. Xu, Z. Lian, P. Brookes and J. M. Xu, Eur. J. Soil Sci., 2016, 67, 40-50.

30 X. Tan, S. Liu, Y. Liu, Y. Gu, G. Zeng, X. Cai, Z. Yan, C. Yang, X. Hu and B. Chen, Sci. Rep., 2016, 6, 39691.
31 B. Fu, C. Ge, L. Yue, J. Luo, D. Feng, H. Deng and H. Yu, BioResources, 2016, 11, 9017-9035.

32 Q. Zhou, Z. Li, C. Shuang, A. Li, M. Zhang and M. Wang, Chem. Eng. J., 2012, 210, 350-356.

33 J. He, J. Dai, T. Zhang, J. Sun, A. Xie, S. Tian, Y. Yan and P. Huo, RSC Adv., 2016, 6, 28023-28033.

34 X. Yang, G. Xu, H. Yu and Z. Zhang, Bioresour. Technol., 2016, 211, 566-573.

35 A. W. Ip, J. P. Barford and G. McKay, Chem. Eng. J., 2010, 157, 434-442.

36 M. J. Ahmed and S. K. Theydan, Chem. Eng. J., 2012, 211, 200-207.

37 J. Rivera-Utrilla, C. V. Gómez-Pacheco, M. Sánchez-Polo, J. J. López-Peñalver and R. Ocampo-Pérez, J. Environ. Manage., 2013, 131, 16-24.

38 L. Qian and B. Chen, J. Agric. Food Chem., 2014, 62, 373-380.

39 B. Li and T. Zhang, Environ. Sci. Pollut. Res., 2013, 20, 30243033.

40 H. Zheng, Z. Y. Wang, J. Zhao, S. Herbert and B. S. Xing, Environ. Pollut., 2013, 181, 60-67.

41 X. Zhu, Y. Liu, C. Zhou, G. Luo, S. Zhang and J. Chen, Carbon, 2014, 77, 627-636.

42 H. Wang, Y. Chu, C. Fang, F. Huang, Y. Song and X. Xue, PLoS One, 2017, 12, e0182776.

43 X. Song, D. Liu, G. Zhang, M. Frigon, X. Meng and K. Li, Bioresour. Technol., 2014, 151, 428-431.

44 W. Chen, L. Duan and D. Zhu, Environ. Sci. Technol., 2007, 41, 8295-8300.

45 X. Zhu, Y. Liu, F. Qian, C. Zhou, S. Zhang and J. Chen, Bioresour. Technol., 2014, 154, 209-214.

46 X. Yuan, Z. Wu, H. Zhong, H. Wang, X. Chen, L. Leng, L. Jiang, Z. Xiao and G. Zeng, Environ. Sci. Pollut. Res., 2016, 23, 18657-18671.

47 M. B. Ahmed, J. L. Zhou, H. H. Ngo and W. Guo, Sci. Total Environ., 2015, 532, 112-126.

48 J. Tolls, Environ. Sci. Technol., 2001, 35, 3397-3406.

49 R. A. Figueroa, A. Leonard and A. A. MacKay, Environ. Sci. Technol., 2004, 38, 476-483. 